\title{
LABEL PRODUK, IKLAN EMOSIONAL, DAN DISKON SERTA PENGARUHNYA TERHADAP KEPUTUSAN PEMBELIAN
}

\author{
Muhammad Akbar Marzuq \\ Universitas Negeri Surabaya \\ muhammadmarzuq16080574053@mhs.unesa.ac.id \\ Anik Lestari Andjarwati \\ Universitas Negeri Surabaya \\ aniklestari@unesa.ac.id
}

Abstract

\begin{abstract}
A brand will carry out several marketing strategies to attract consumers. especially for countries with a Muslim majority community, the product must have halal legality. There are several factors considered by consumers to choose the product purchased, among others, the existence of halal labels on packaging, emotional advertising, and diskons. The purpose of this paper is to study the effect of product labels, emotional advertising, and discount on purchasing decisions. This research is focused on consumers who have bought Chatime as a bubble drink, Muslim, aged 15-60 years old, and a final consumer. uses a nonprobability sampling technique. Questionnaires were distributed to 200 participants with Google form. Data analysis techniques using Multiple Linear Regression. The results showed that product labels, iklan emosional, and diskons had a positive effect on consumer purchasing decisions.
\end{abstract}

Keywords: emotional advertising; halal label; product label; discount; purchase decision.

\section{PENDAHULUAN}

Industri makanan dan minuman di Indonesia menjadi primadona bagi perusahaan, terutama perusahaan waralaba. Hal ini dikarenakan permintaan makanan dan minuman yang menjadi kebutuhan sehari-hari setiap manusia. Kementerian Perindustrian mencatat, sumbangan industri makanan dan minuman kepada PDB industri non-migas mencapai 34,95 persen pada triwulan III tahun 2017. Hasil kinerja ini menjadikan sektor tersebut kontributor PDB industri terbesar dibanding subsektor lainnya. Banyaknya perusahaan waralaba yang masuk ke pasar Indonesia tidak hanya berasal dari waralaba domestik tetapi waralaba asing pun ikut melebarkan sayapnya ke pasar Indonesia. Jumlah Waralaba yang ada di Indonesia tercatat mencapai 480-500 merek untuk waralaba asing. Sedangkan yang asli domestik hanya 120 merek pada 2019. Pertumbuhan penjualan waralaba hingga akhir tahun 2018 mencapai 5\%-6\%. Berdasarkan hasil survey yang dilakukan oleh Asosiasi Franchise Indonesia (AFI), franchise asli Indonesia tidak ada pertumbuhan (stagnan), walaupun permintaan tinggi tetapi perusahaan franchise asli Indonesia tidak ada pertumbuhan yang signifikan. Stagnansi pada waralaba lokal bertolak belakang dengan waralaba asing yang berkembang di pasar Indonesia (Wijayanto, 2019). Tingginya persaingan bisnis dan banyaknya kompetitor di industri waralaba minuman mengharuskan suatu perusahaan mengetahui perilaku dari konsumen di Indonesia, sehingga bisa membuat produk yang unik, sesuai dengan kebutuhan dan keinginan konsumen (Palupi, 2020).

Menurut Sumarwan (2015:9), salah satu perilaku konsumen yang penting adalah keputusan pembelian. Hal ini dikarenakan seluruh kegiatan produksi hingga pemasaran bertujuan agar konsumen melakukan keputusan pembelian. Menurut Sumarwan (2015:9-15), terdapat 3 faktor utama yang memengaruhi keputusan pembelian yaitu perbedaan individu, faktor lingkungan dan strategi pemasaran. Dalam menentukan strategi pemasaran, perusahaan juga perlu memperhatikan bauran pemasaran. Menurut Kotler \& Armstrong (2008:62), pengertian bauran pemasaran adalah kumpulan alat pemasaran taktis terkendali yang dipadukan perusahaan untuk menghasikan respon yang diinginkannya dipasar sasaran. Terdapat 4 aspek dalam bauran pemasaran untuk produk barang yaitu 4P (Place, Price, Promotion dan Product). Aspek tempat (place) pada bauran pemasaran merupakan tempat usaha merupakan lokasi di mana proses jual beli terjadi, aspek harga (price) nilai yang harus diberikan konsumen untuk mendapatkan barang atau jasa yang dijual, selanjutnya yang dimaksud promosi (promotion) adalah 
kegiatan bisnis yang mempunyai tujuan agar konsumen bisa lebih mengenal dan tertarik dengan produk yang dijual. Yang terakhir adalah produk (product) yakni hal yang dijual dalam bisnis meliputi barang atau jasa yang memiliki nilai guna dan dibutuhkan oleh konsumen.

Menurut Kotler \& Armstrong (2008:62), variabel bauran pemasaran memiliki 4 aspek salah satunya yaitu produk. Lebih lanjut, menurut Kotler \& Armstrong (2012:255), suatu produk biasanya diikuti oleh serangkaian atribut-atribut yang menyertai produk meliputi beberapa hal yaitu kualitas produk, fitur produk, gaya dan design produk, merek, kemasan, label, dan pelayanan pendukung produk. Label produk yang dimaksud di sini adalah bagian dari pengemasan sebuah produk yang mengandung informasi mengenai produk atau penjualan produk termasuk informasi tentang kehalalan suatu produk. Kehalalan menjadi sesuatu yang dipertimbangkan di Negara Indonesia mengingat mayoritas penduduk beragama islam. Kehalalan suatu produk dapat dilihat pada label makanan dan minuman yang mendapatkan cap atau logo halal dari MUI (Majelis Ulama Indonesia). Menurut Tjiptono (2008:103), atribut produk adalah unsur-unsur produk yang dianggap penting oleh konsumen dan dijadikan dasar pengambilan keputusan, salah satunya ialah label halal. Beberapa penelitian yang membahas pengaruh label terhadap keputusan pembelian di antaranya Ribeiro et al. (2018), Nasution \& Rossanty (2018) dan Muzhar et al. (2018) yang hasil penelitiannya menunjukkan bahwa label produk memengaruhi keputusan pembelian konsumen. Tidak serta merta label dapat memengaruhi keputusan pembelian bergantung fkepada setiap individu itu sendiri.

Menurut Kotler \& Armstrong (2008:62), selain produk variabel bauran pemasaran yang memengaruhi keputusan pembelian adalah promosi. Menurut Tjiptono (2008:221), promosi merupakan elemen bauran pemasaran yang berfokus pada upaya menginformasikan, membujuk, dan mengingatkan kembali konsumen akan merek dan produk perusahaan. Kotler \& Keller (2009:174) mengatakan bahwa unsur komunikasi bauran promosi (promotion mix) terdiri atas 8 unsur, yaitu advertising (iklan), sales promotion, public relation \& publicity, personal selling, direct marketing, acara dan pengalaman, pemasaran interaktif pemasaran dai mulut ke mulut. Dalam kaitannya dengan pemasaran, iklan dianggap sangat efektif untuk menyampaikan informasi dan stimulus akan produk, maka banyak pemasar melakukan iklan sebagai media promosi.

Kotler \& Armstrong (2008:7) menyatakan bahwa iklan harus menemukan daya tarik iklan yang tepat agar menghasilkan tanggapan yang diinginkan. Terdapat 2 daya tarik iklan yaitu rasional dan emosional. Pemasar menggunakan iklan emosional untuk berusaha mengendalikan emosi negatif atau positif yang dapat memotivasi konsumen. Seperti halnya takut dan malu yang mendorong orang melakukan hal-hal yang seharusnya mereka lakukan atau berhenti melakukan hal-hal yang seharusnya tidak mereka lakukan. Pemasar juga menggunakan daya tarik emosional positif seperti cinta, humor, kebanggaan, dan kegembiraan. Terdapat beberapa penelitian tentang pengaruh iklan emosional di antaranya Fah et al. (2011) yang menunjukkan bahwa iklan emosional memiliki pengaruh yang signifikan terhadap pembelian konsumen dan Kamran \& Siddiqui (2019) yang menunjukkan bahwa iklan emosional berpengaruh pada perilaku keputusan pembelian.

Selain iklan, menurut Kotler \& Armstrong (2008:62), variabel bauran pemasaran yang kerap digunakan oleh perusahaan adalah sales promotion. Dalam sales promotion terdapat promotion tools yang kerap digunakan yaitu diskon. Menurut Kotler \& Keller (2009:93), diskon adalah harga resmi yang diberikan perusahaan kepada konsumen yang bersifat lunak demi meningkatkan penjualan suatu produk barang atau jasa. Menurut Tjiptono (2008:166), diskon merupakan potongan harga yang diberikan oleh penjual kepada pembeli sebagai penghargaan atas aktivitas tertentu dari pembeli yang menyenangkan bagi penjual. Terdapat beberapa penelitian tentang pengaruh diskon terhadap keputusan pembelian di antaranya Ahmad et al. (2015) yang menunjukkan bahwa diskon berpengaruh positif pada perilaku pembelian pelanggan, Shamout (2016) yang menunjukkan bahwa diskon memiliki pengaruh yang signifikan terhadap pembelian konsumen, dan K'ombwayo \& Iravo (2018) dalam penelitiannya menunjukkan bahwa diskon memberikan pengaruh signifikan positif terhadap keputusan pembelian konsumen. 
Muhammad Akbar Marzuq \& Anik Lestari Andjarwati. Label Produk, Iklan Emosional, dan Diskon serta Pengaruhnya terhadap Keputusan Pembelian

Dalam industri makanan dan minuman, muncul waralaba minuman kekinian yaitu minuman bubble drink. Minuman ini diterima cukup baik dan cukup digandrungi oleh remaja-remaja. Beberapa merek bubble tea yang ada di Indonesia antara lain Chatime, KOI dan Quickly. Chatime bisa dibilang salah satu brand yang memperkenalkan lembutnya bubble kepada lidah masyarakat Indonesia. Brand minuman asal Taiwan ini telah ada di Indonesia sejak 2011, di bawah naungan Kawan Lama Group. Menurut Feronica Wibowo, Direktur Chatime Indonesia, hingga kini Chatime telah memiliki 274 gerai yang tersebar di 32 kota di Indonesia (KumparanFOOD, 2019). Chatime menjadi merek minuman bubble drink nomor 1 selama 5 tahun berturut-turut dari tahun 2016 hingga 2020 berdasarkan Top Brand Index (TBI). Parameter top brand adalah top of market share, top of mind share, serta top of commitment share. Market share di sini adalah bagian atau persentase penjualan suatu produk atau jasa tertentu dalam suatu wilayah yang dikendalikan oleh suatu perusahaan. Pesaing Chatime yaitu Lup-Lup memiliki lebih banyak gerai jika dibandingkan dengan Chatime serta sertifikat halal yang lebih dulu didapatkan seharusnya membuat masyarakat Indonesia lebih memilih Lup-Lup ketimbang Chatime, mengingat sebagian besar masyarakat Indonesia beragama islam, tetapi pada kenyataannya berbanding terbalik. Penjualan Chatime yang terus meningkat terlihat dengan terus dibukanya gerai-gerai Chatime baru di Indonesia yang menjadikan market share dari Chatime bertambah tinggi setiap tahunnya sehingga bisa menjadi top brand no 1 versi (Top Brand Index, 2020).

Hal lain yang menjadikan Chatime menjadi top brand selama 5 tahun berturut-turut ialah promosi yang dilakukan. Bentuk promosi yang diberikan kepada konsumen ialah sales promotion (voucher dan diskon)(Majalah Serpong Update, 2018) dan iklan melalui social media instagram. Menetapkan harga ganjil yang sedikit lebih murah dari harga yang ditentukan agar konsumen mengira produk yang dibeli lebih murah, Untuk itu menggunakan strategi penetapan harga yang paling sesuai dengan produk yang ada. Pemberian potongan harga tertentu apabila konsumen membeli produk dalam jumlah banyak, juga dapat dijadikan strategi khusus untuk menarik keputusan pembelian (Tjiptono, 2008:151) Melihat hal tersebut Chatime melakukan strategi promosi penjualan dengan memberikan diskon harga untuk produk tertentu dan dalam kurun waktu tertentu(Chatime, 2020). Pemberian harga diskon ini juga digunakan untuk tetap bisa bertahan dan bersaing dengan kompetitor lainnya seperti Hop-Hop dan Lup-Lup. Tidak hanya menggunakan diskon sebagai strategi pemasaran penjualannya, Chatime menggunakan media periklanan sebagai sarana menyampaikan informasi apabila terdapat produk baru dan dan promosi penjualan lainnya (Kontan, 2017). Iklan yang dipilih untuk digunakan oleh Chatime ialah iklan yang menyentuh sisi emosional konsumen melalui iklan emosional.

Berdasarkan latar belakang yang telah dijelaskan, rumusan masalah dalam penelitian ini adalah sebagai berikut. (1) Adakah pengaruh label halal pada produk Chatime terhadap keputusan pembelian? (2) Adakah pengaruh iklan emosional yang digunakan produk Chatime terhadap keputusan pembelian? (3) Adakah pengaruh diskon pada produk Chatime terhadap keputusan pembelian?

\section{KAJIAN PUSTAKA DAN PENGEMBANGAN HIPOTESIS}

\section{Keputusan Pembelian}

Menurut Kotler \& Keller (2009:181), pengertian dari keputusan pembelian adalah membeli merek yang paling disukai, tetapi dua faktor bisa berbeda antara niat pembelian dan keputusan pembelian. Tjiptono (2008:19) Mengemukakan bahwa keputusan pembelian konsumen adalah pembelian suatu tindakan dari dua atau lebih pilihan alternatif. Mowen \& Minor (2002:11) mendefinisikan keputusan pembelian konsumen sebagai serangkaian langkah-langkah tertentu pada saat melakukan pembelian.

Untuk mengukur variabel keputusan pembelian menggunakan indikator Ahmad et al. (2015), Kamran \& Siddiqui (2019), dan Nasution \& Rossanty (2018) dengan penyesuaian dari objek yang diteliti dengan indikator sebagai berikut. (1) Merasa aman untuk membeli makanan berlabel halal. (2) Merasa produk makanan halal memiliki kualitas dan kebaikan. (3) Probabilitas yang dipertimbangkan untuk membeli suatu merek yang menggunakan daya tarik emosional yang tinggi. (4) Iklan emosional memengaruhi keputusan pembelian. (5) Membeli lebih banyak pada barang potongan harga (6) Biasanya membeli produk dengan potongan harga. 


\section{Label Produk}

Menurut Kotler \& Keller (2009:29), label merupakan gantungan sederhana pada produk atau gambar yang disusun dengan rumit yang menjadi bagian kemasan. Menurut Tjiptono (2008:107), label adalah atribuk suatu produk yang menyampaikan informasi terkait produk dan penjualnya. Sebuah label menjadi bagian dari kemasan, atau bisa menjadi etiket (tanda pengenal) yang digantungkan pada produk. Lebih lanjut, Menurut Kotler \& Keller (2009:29) Fungsi dari label produk di antaranya sebagai berikut. (1) Label mengidentifikasi produk atau merek, (2) Label menentukan kelas produk, (3) Label menggambarkan beberapa hal mengenai produk (siapa pembuatnya, di mana dibuat, kapan dibuat, apa isinya, bagaimana menggunakannya, dan bagaimana menggunakan secara aman), (4) Label mempromosikan produk lewat aneka gambar yang menarik.

Menurut Simamora (2000:502), label dikategorikan menjadi beberapa jenis, yaitu sebagai berikut. (1) Label produk (product label) adalah bagian dari kemasan sebuah produk yang berisi informasi terkait suatu produk, (2) Label merek (brand label) adalah nama merek yang diletakkan pada kemasan suatu produk, (3) Label tingkat (grade label) untu mengetahui mutu produk, label ini terdiri dari huruf, angka atau metode lainya untuk menunjukkan tingkat kualitas dari produk itu sendiri, (4) Label deskriptif (descriptive label) menggambarkan isi, pemakaian dan ciri-ciri produk. Pemberian label (labeling) ialah sesuatu yang sangat penting dan patut memperoleh perhatian lebih dengan tujuan untuk menarik para konsumen.

Dalam penelitian ini, label produk yang dimaksud adalah label halal. Menurut Apriyantono (2003:68) dalam jIlsanti, Rachma, \& Hufron (2019) label halal termasuk kedalam label produk di mana label produk terdiri atas nama merek produk, keterangan bahan dan komposisi, informasi gizi, tanggal kadaluwarsa, isi produk, dan keterangan legalitas suatu produk salah satunya ialah sertifikat halal. Menurut Tjiptono (2008:103), atribut produk adalah unsur-unsur produk yang dianggap penting oleh konsumen dan dijadikan dasar pengambilan keputusan. Menurut Ribeiro, Carneiro, Ramos, Patterson, \& Pinto (2018), Nasution \& Rossanty (2018) dan Muzhar, Santoso, \& Rusdan (2018) membuktikan bahwa label produk memengaruhi keputusan pembelian konsumen.

H1: Label halal pada produk Chatime berpengaruh terhadap keputusan pembelian kosumen.

\section{Iklan emosional}

Menurut Belch (2009:276) dalam Fajriani, Suharyono, \& Bafadhal (2018) mendefinisikan iklan emosional memiliki daya tarik yang memengaruhi kebutuhan sosial dan psikologis sehingga konsumen memiliki motivasi yang lebih terhadap produk yang diiklankan.

Menurut Kertamukti (2015:155) dalam Limbong \& Winarni (2017), emotional appeals (daya tarik emosional) adalah sebuah pendekatan yang dapat digunakan dalam pembuatan iklan. Daya tarik emosional berusaha untuk memanfaatkan emosi positif dan emosi negatif. Daya tarik emosional mendorong khalayak untuk menggunakan emosinya.

Menurut (Kotler 2004) dalam Fajriani, Suharyono, \& Bafadhal (2018) menjelaskan terdapat beberapa daya tarik emosional dalam iklan. Emosi positif (humor, cinta, bangga, dan kesenangan) dan negatif (ketakutan, rasa, bersalah, dan malu). Menurut William (2000) dalam Kamran \& Siddiqui (2019), terdapat 7 tipe dalam iklan emosional yaitu excitement (kegembiraan), fear (ketakutan), humor, love (cinta), sad (sedih), and angry (marah).

Beberapa penelitian tentang pengaruh iklan emosional di antaranya Fah, Foon, \& Osman (2011) yang menunjukkan bahwa iklan emosional memiliki pengaruh yang signifikan terhadap pembelian konsumen dan Kamran \& Siddiqui (2019) yang menunjukkan bahwa iklan emosional berpengaruh pada perilaku keputusan pembelian.

H2: Iklan emosional yang digunakan Chatime berpengaruh terhadap keputusan pembelian konsumen. 
Muhammad Akbar Marzuq \& Anik Lestari Andjarwati. Label Produk, Iklan Emosional, dan Diskon serta Pengaruhnya terhadap Keputusan Pembelian

\section{Diskon}

Menurut Tjiptono (2008:166), diskon merupakan potongan harga yang diberikan oleh penjual serta sebagai penghargaan karena telah membeli suatu produk. Menurut Kotler \& Keller (2009:223) penurunan harga adalah diskon langsung dari harga resmi untuk setiap pembelian sepanjang periode waktu yang ditentukan. Lebih lanjut, Kotler \& Keller (2009:93) menjelaskan diskon adalah pengurangan harga bagi pembeli yang membayar tagihan tepat waktu.

Menurut Kotler \& Keller (2009:93), diskon ialah pengurangan harga bagi pembeli yang membayar tagihannya tepat waktu. Terdapat beberapa jenis diskon yaitu sebagai berikut. (1) Diskon fungsional, diskon yang ditawarkan oleh produsen ke anggota saluran dagang. (2) Diskon musiman, pengurangan harga kepada mereka yang membeli barang atau jasa di luar musim. (3) Diskon kuantitas pengurangan harga kepada mereka yang membeli barang atau jasa dalam volume besar.

Terdapat beberapa penelitian tentang pengaruh diskon di antaranya Ahmad et al. (2015) yang menunjukkan bahwa diskon berpengaruh positif pada perilaku pembelian pelanggan, Shamout (2016) yang menunjukkan bahwa diskon memiliki pengaruh yang signifikan terhadap pembelian konsumen, dan K'ombwayo \& Iravo (2018) dalam penelitiannya menunjukkan bahwa diskon memberikan pengaruh signifikan positif terhadap keputusan pembelian konsumen. Kerangka konseptual yang digunakan dalam penelitian ini ditunjukkan pada Gambar 1.

H3: Diskon pada produk Chatime berpengaruh terhadap keputusan pembelian konsumen.

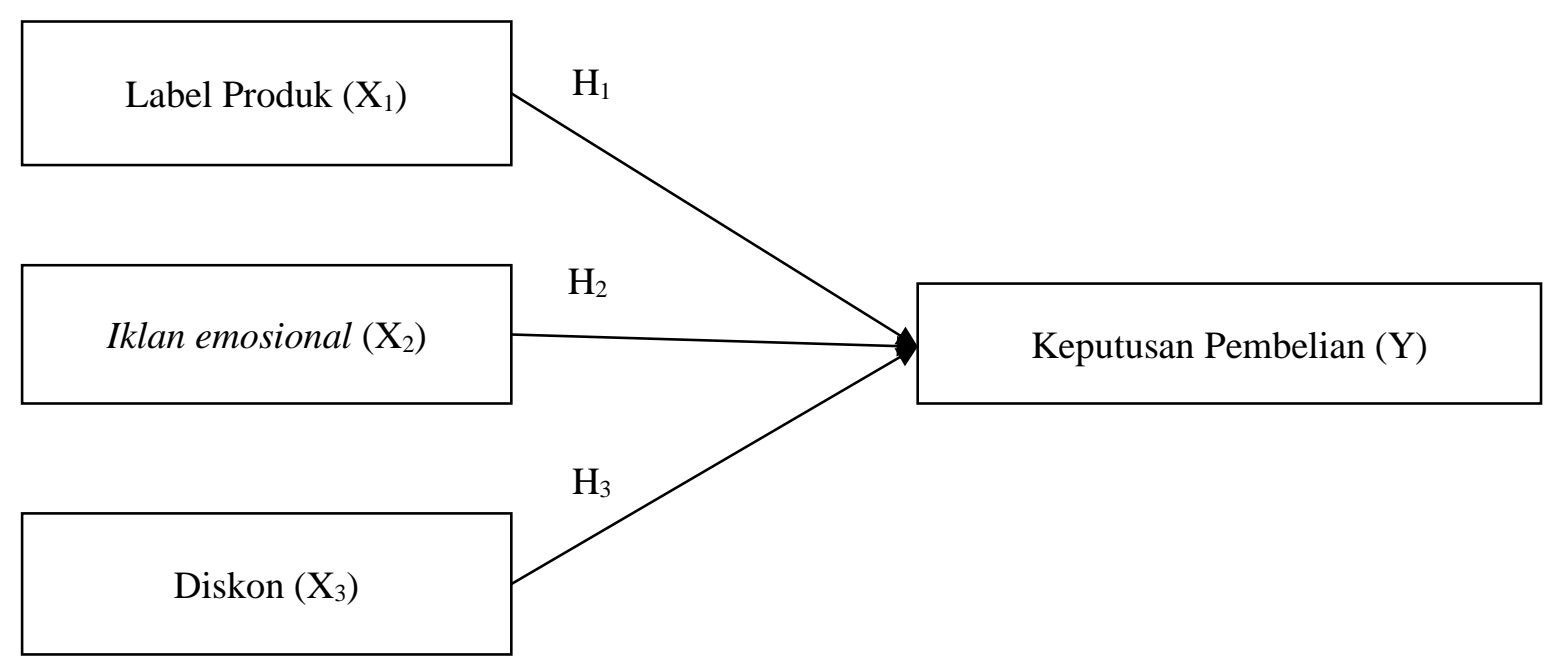

Gambar 1. KERANGKA KONSEPTUAL

\section{METODE PENELITIAN}

Penelitian ini adalah penelitian konklusif kausalitas di mana tujuan utamanya untuk mendapatkan pembuktian mengenai adanya pengaruh dari variabel bebas antara lain label produk, iklan emosional, diskon terhadap variabel terikat yaitu keputusan pembelian. Populasi dalam penelitian ini adalah konsumen minuman bubble drink Chatime di Jalan Raya Darmo dengan kriteria, yaitu sudah pernah membeli minuman bubble drink Chatime, berumur 15 - 60 tahun, beragama Islam, merupakan konsumen akhir. Sampel dalam penelitian ini adalah konsumen minuman bubble drink Chatime di Jalan Raya Darmo dengan jumlah 200 responden menggunakan teknik pengambilan sampel non-probability sampling yaitu metode judmental sampling. Data diperoleh dari penyebaran angket online kepada responden yang sesuai dengan karakteristik populasi. Variabel, indikator, dan item pernyataan yang digunakan dalam penelitian ini yang ditunjukkan pada tabel 1. Teknik analisis data dalam penelitian ini menggunakan Regresi Linear Berganda dan diolah dengan program SPSS 23.0. 


\section{VARIABEL, INDIKATOR DAN ITEM PENELITIAN}

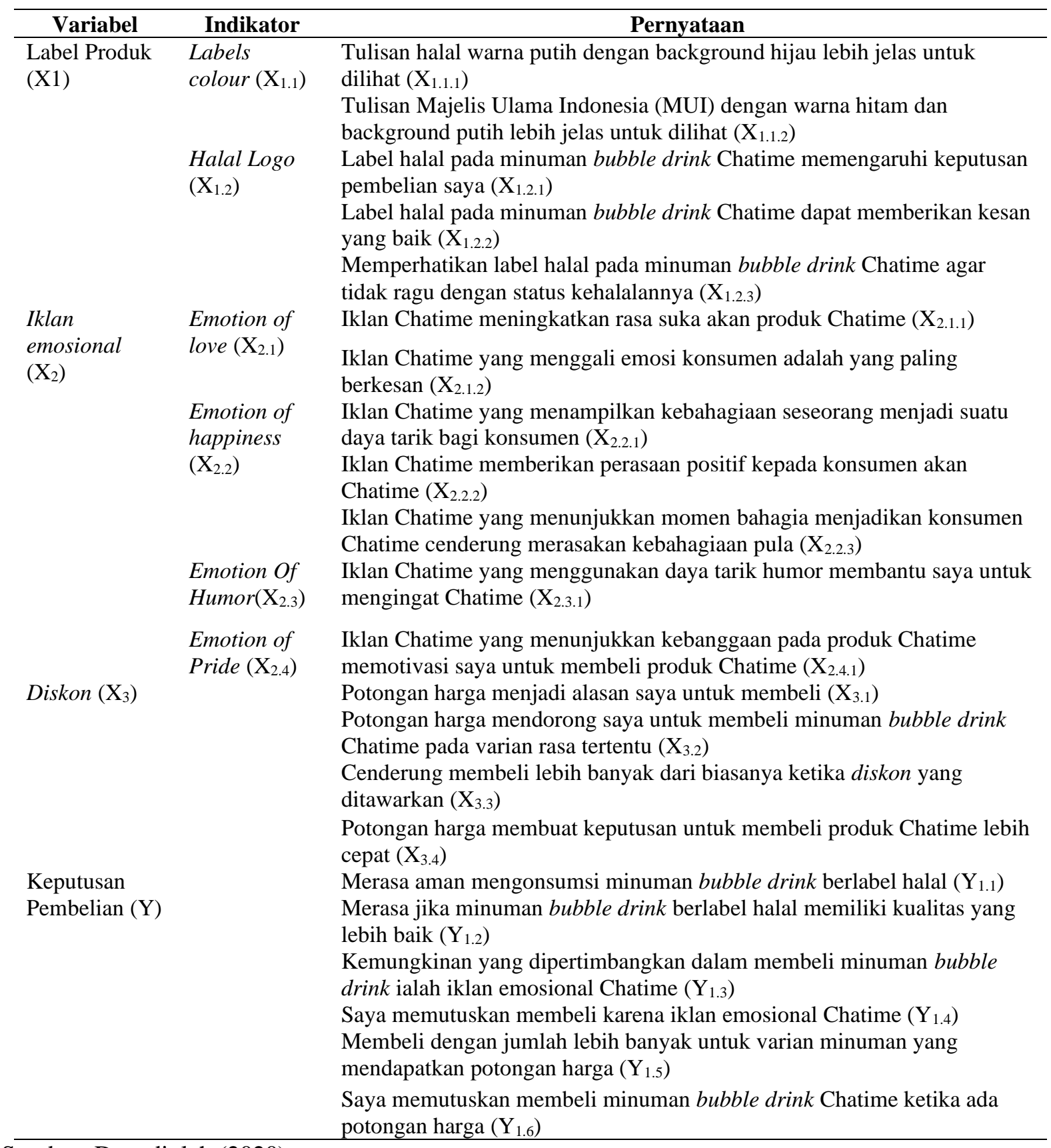

Sumber: Data diolah (2020)

\section{HASIL DAN PEMBAHASAN}

\section{Deskripsi Responden}

Responden dalam penelitian ini adalah konsumen minuman bubble drink Chatime di Jalan Raya Darmo yang telah membeli minuman bubble drink Chatime, berumur 15-60 tahun, beragama Islam, dan merupakan konsumen akhir. Deskripsi responden dalam penelitian ini berdasarkan jenis kelamin, pekerjaan, penghasilan, dan usia. 200 responden dalam penelitian ini didominasi oleh perempuan sebanyak $75,5 \%$ dan laki-laki $24,5 \%$ sedangkan usia responden yang paling banyak ialah usia 15-25 tahun dengan status pekerjaan sebagai pelajar/mahasiswa yang memiliki penghasilan di bawah 1,5 juta. 
Muhammad Akbar Marzuq \& Anik Lestari Andjarwati. Label Produk, Iklan Emosional, dan Diskon serta Pengaruhnya terhadap Keputusan Pembelian

\section{Hasil Uji Validitas dan Reliabilitas}

Uji validitas pada penelitian ini dilakukan dengan cara menyebarkan angket atau kuesioner kepada 30 orang. Pengukuran validnya suatu item dilihat dari nilai korelasi antara item terhadap nilai valid. Jika $\mathrm{r}$ hitung > $\mathrm{r}$ tabel dan bernilai positif, maka pernyataan atau indikator tersebut dapat dinyatakan valid (Ghozali, 2016:53), diketahui bahwa terdapat satu item pernyataan $\left(\mathrm{X}_{3.4}\right)$ yang memiliki $\mathrm{r}$ hitung < $\mathrm{r}$ tabel sehingga dinyatakan tidak valid. Namun, untuk 21 item pernyataan yang lain memiliki nilai $r$ hitung > $r$ tabel sehingga dinyatakan valid dan dapat digunakan untuk melakukan pengukuran pengaruh label produk, iklan emosional, dan diskon terhadap keputusan pembelian.

Pengujian reliabilitas dalam penelitian ini dilakukan kepada 30 orang yang sama dengan uji validitas. Reliabilitas suatu variabel dapat dikatakan reliabel jika memiliki nilai Cronbach's Alpha > 0,70 (Sugiyono, 2017:134). Berdasarkan hasil uji reliabilitas, dapat diketahui besarnya nilai Cronbach's Alpha untuk setiap variabel >0,70 yang menunjukkan bahwa pernyataan yang dibuat pada instrumen penelitian adalah reliabel dan dapat digunakan sebagai alat ukur.

\section{Hasil Uji Asumsi Klasik}

Tabel 2.

\section{HASIL UJI ASUMSI KLASIK}

\begin{tabular}{|c|c|c|c|}
\hline No & Asumsi Klasik & Hasil Perhitungan & Keterangan \\
\hline 1. & Uji Normalitas & $\begin{array}{l}\text { Nilai Asymp. Sig. (2-tailed) dalam Signifikansi } \\
\text { Uji Kolmogrov-Smirnov sebesar } 0,200 \\
\text { sehingga }>0,05\end{array}$ & $\begin{array}{l}\text { Model regresi linear berganda } \\
\text { memenuhi asumsi normalitas }\end{array}$ \\
\hline 2. & $\begin{array}{c}\text { Uji } \\
\text { Multikolonieritas }\end{array}$ & $\begin{array}{l}\text { Nilai tolerance pada semua variabel sebesar } \\
0,926,0,822 \text { dan } 0,856 \text { sehingga } \geq 0,01 \text { dan nilai } \\
\text { VIF sebesar } 1,079,1,217 \text {, dan } 1,168 \text { atau } \leq 10 \text {. }\end{array}$ & $\begin{array}{l}\text { Model regresi linear berganda } \\
\text { memenuhi asumsi } \\
\text { multikolonieritas }\end{array}$ \\
\hline 3. & $\begin{array}{c}\mathrm{Uji} \\
\text { Heteroskesdasitas }\end{array}$ & $\begin{array}{l}\text { Nilai sig. (2-tailed) pada X1 sebesar } 0,840 \text { atau } \\
>0,05 \text { dan pada X2 sebesar } 0,290 \text { atau }>0,05 \text {, } \\
\text { dan pada X3 sebesar } 0,522 \text { atau }>0,05 \text {. }\end{array}$ & $\begin{array}{l}\text { Model regresi linear berganda } \\
\text { memenuhi asumsi } \\
\text { heteroskesdasitas }\end{array}$ \\
\hline
\end{tabular}

Sumber: Data diolah (2020)

Berdasarkan tabel 2, dapat dilihat bahwa penelitian ini telah dilengkapi dengan asumsi normalitas, asumsi multikolonieritas, dan asumsi heteroskesdasitas. Selanjutnya, dilakukan uji regresi linear berganda untuk mengetahui pengaruh variabel label produk, iklan emosional, dan diskon terhadap keputusan pembelian konsumen. Berikut ini hasil pengolahan data berdasarkan uji regresi linear berganda, adjusted $R$ square, dan uji parsial dengan menggunakan program SPSS 23.0. Berdasarkan hasil analisis data pada tabel 3, maka diperoleh model persamaan linear berganda pada rumus (1).

$\mathrm{Y}=1.871+0,300 \mathrm{X} 1+0,193 \mathrm{X} 2+0,815 \mathrm{X} 3$

Keterangan:

$\mathrm{Y}=$ Keputusan Pembelian

$\mathrm{X}_{1}=$ Label Produk

$\mathrm{X}_{2}=$ Iklan emosional

$\mathrm{X}_{3}=$ Diskon

\section{Hasil Uji Kelayakan Model (Adjusted R Square)}

Hasil pembahasan pengaruh label produk, iklan emosional, dan diskon terhadap keputusan pembelian Chatime menghasilkan $\mathrm{R}$ (korelasi) dan $\mathrm{R}^{2}$ (Adjusted $R$ Square). Dari tabel 3 dapat dijelaskan bahwa nilai kontribusi atau nilai Adjusted $\mathrm{R}^{2}$ untuk variabel independen yaitu label produk (X1), iklan emosional (X2), dan diskon (X3) terhadap variabel dependen yaitu keputusan pembelian Chatime (Y) sebesar 0,574 atau sebesar $57 \%$. Artinya label produk, iklan emosional, dan diskon memiliki proporsi pengaruh terhadap niat berkunjung sebesar $57 \%$ dan sisanya $43 \%$ dipengaruhi oleh variabel lain yang tidak termasuk dalam penelitian. 
Tabel 3.

HASIL UJI HIPOTESIS

\begin{tabular}{lccccccc}
\hline Uji Hipotesis & $\mathbf{B}$ & $\begin{array}{c}\text { Std } \\
\text { Error }\end{array}$ & $\begin{array}{c}\text { Standardized } \\
\text { Coefficients }\end{array}$ & $\begin{array}{c}\mathbf{R} \\
\text { square }\end{array}$ & $\begin{array}{c}\text { Adjusted } \\
\text { R Square }\end{array}$ & t & Sig. \\
\hline Regresi Linear Berganda & & & & & & & \\
$\quad$ (Constant) & 1.871 & 1.407 & & & & & \\
Label Produk & .300 & .056 & .259 & & & & \\
$\quad$ Iklan emosional & .193 & .035 & .283 & & & & \\
$\quad$ Diskon & .815 & .082 & .497 & & & & \\
Adjusted $R$ Square & & & & .581 & .574 & & \\
Uji Parsial & & & & & & 1.329 & .185 \\
(Constant) & & & & & & 5.382 & .000 \\
Label Produk & & & & & & 5.547 & .000 \\
Iklan emosional & & & & & & 9.952 & .000 \\
Diskon & & & & & & &
\end{tabular}

Sumber: Data diolah (2020)

\section{Hasil Pengujian Hipotesis (Uji-t)}

Berdasarkan tabel 3, label halal pada produk Chatime memiliki nilai t-hitung sebesar 5,382 dengan signifikansi 0,000 di mana nilai $\alpha$ tersebut memiliki nilai lebih kecil dari 0,05 . Nilai tersebut menjelaskan bahwa $\mathrm{H}_{0}$ ditolak dan $\mathrm{H}_{\mathrm{a}}$ diterima artinya hipotesis pertama diterima, sehingga terdapat pengaruh dari label halal pada produk Chatime terhadap keputusan pembelian. Hasil penelitian menunjukkan bahwa terdapat pengaruh iklan emosional yang digunakan produk Chatime terhadap keputusan pembelian. Penelitian ini juga membuktikan terdapat pengaruh diskon pada produk Chatime terhadap keputusan pembelian.

\section{Pengaruh Label Produk terhadap Keputusan Pembelian Konsumen}

Hasil penelitian ini menunjukkan bahwa variabel label produk memiliki pengaruh signifikan terhadap keputususan pembelian konsumen. Pengaruh dari label produk terhadap keputusan pembelian memiliki nilai yang positif dan menunjukkan hubungan searah. Hal tersebut menjelaskan bahwa apabila kualitas dari label produk produk Chatime terus ditingkatkan dan diinovasikan, maka keputusan pembelian Chatime akan semakin meningkat pula.

Hasil penelitian ini sesuai dengan teori Tjiptono (2008:103) yang menjelaskan bahwa atribut produk merupakan unsur produk yang dianggap penting oleh konsumen dan dijadikan dasar dari pengambilan keputusan. Hasil penelian ini juga mendukung hasil penelitian terdahulu yang dilakukan Ribeiro et al., (2018) yang menyatakan bahwa pengemasan dan label produk memengaruhi perilaku konsumen dalam kaitannya dengan pengambilan keputusan. Hasil penelitian ini juga selaras dengan hasil penelitian yang dilakukan oleh Putra et al., (2018) dan Ahmad et al. (2018) yang menunjukkan bahwa label produk memengaruhi keputusan pembelian konsumen.

Variabel label produk dalam penelitian ini diukur menggunakan dua indikator yaitu labels colour dan halal logo. Berdasarkan item-item pernyataan untuk variabel label produk, item pernyataan yang memiliki nilai tertinggi adalah "Label halal pada minuman bubble drink Chatime dapat memberikan kesan yang baik". Hal ini menunjukkan bahwa rata-rata responden percaya adanya label halal memberikan kesan yang baik pada Chatime, sehingga hal tersebut juga yang mendorong konsumen untuk mengambil keputusan pembelian. Dengan adanya hasil penelitian ini, maka pengelola chatime dapat lebih menekankan label halal pada produk mereka, selain dikarenakan iklan emosional dan diskon mampu memengaruhi keputusan pembelian konsumen, label halal tersebut dapat membuat konsumen lebih percaya terhadap kehalalan produk Chatime mengingat mayoritas konsumen Indonesia beragama Islam. 
Muhammad Akbar Marzuq \& Anik Lestari Andjarwati. Label Produk, Iklan Emosional, dan Diskon serta Pengaruhnya terhadap Keputusan Pembelian

\section{Pengaruh Iklan emosional terhadap Keputusan Pembelian Konsumen}

Hasil penelitian menunjukkan bahwa variabel iklan emosional memiliki pengaruh signifikan terhadap keputusan pembelian konsumen. Pengaruh dari variabel iklan emosional terhadap keputusan pembelian memiliki nilai yang positif dan menunjukkan hubungan yang searah, yang artinya apabila iklan Chatime yang mengandung daya tarik emosional melalui media sosial instagram terus ditingkatkan, maka keputusan pembelian konsumen akan semakin meningkat. Hasil penelitian ini sejalan dengan hasil penelitian terdahulu yang dilakukan oleh Fah et al., (2011) yang menyatakan bahwa iklan yang memiliki daya tarik emosional memiliki pengaruh yang signifikan terhadap pembelian konsumen. Hasil penelitian ini juga mendukung penelitian dilakukan oleh Kamran et al., (2019) yang menunjukkan bahwa iklan emosional berpengaruh pada pengambilan keputusan pembelian konsumen.

Variabel iklan emosional dalam penelitian ini diukur menggunakan empat indikator yaitu emotion of love, emotion of happiness, emotion of humor, emotion of pride dan item pernyataan yang memiliki nilai rata-rata tertinggi adalah "Iklan Chatime yang menampilkan kebahagiaan seseorang menjadi suatu ketertarikan kepada Chatime". Hal ini menunjukkan bahwa secara rata-rata, responden percaya bahwa dengan adanya iklan Chatime yang menampilkan kebahagiaan akan menarik responden untuk membeli produk dari Chatime. Sehingga apabila Iklan Chatime yang menampilkan kebahagiaan terus ditingkatkan, hal tersebut akan mendorong peningkatan ketertarikan konsumen pada Chatime.

\section{Pengaruh Diskon terhadap Keputusan Pembelian Konsumen}

Hasil penelitian menunjukkan bahwa variabel diskon memiliki pengaruh terhadap keputusan pembelian konsumen. Pengaruh variabel diskon terhadap keputusan pembelian menunjukkan nilia yang yang positif dan memiliki hubungan yang searah. Artinya pemberian potongan harga yang terus-menerus akan meningkatkan pengambilan keputusan konsumen untuk membeli minuman bubble drink Chatime. Hasil penelitian ini mendukung hasil penelitian yang dilakukan oleh Ahmad et al,. (2015) yang menunjukkan bahwa diskon memberikan pengaruh positif dan signifikan terhadap keputusan pembelian konsumen.

Variabel diskon dalam penelitian ini diukur dengan menggunakan tiga item. Nilai rata-rata dari ketiga item tersebut menunjukkan bahwa rata-rata responden setuju dengan pernyataan yang diberikan. Item pernyataan yang memiliki nilai rata-rata tertinggi adalah "Potongan harga menjadi alasan saya untuk membeli". Hal ini menunjukkan bahwa rata-rata responden melakukan pembelian minuman bubble drink Chatime karena adanya pemberian potongan harga atau diskon. Sehingga apabila promosi dengan melakukan diskon cukup sering dilakukan, hal tersebut akan mendorong peningkatan keputusan konsumen untuk melakukan pembelian minuman bubble drink Chatime. hal ini sesuai dengan hasil data responden yang menunjukkan bahwa keputusan pembelian pada minuman bubble drink Chatime mayoritas dilakukan oleh konsumen perempuan pada usia 15-25 tahun, di mana pada usia tersebut konsumen memiliki rasa penasaran yang menyebabkan rasa ingin mencoba sesuatu yang baru namun dengan harga yang murah. Dengan adanya diskon oleh pengelola Chatime akan menimbulkan keputusan pembelian dari konsumen.

\section{KESIMPULAN}

Variabel label produk (X1) pada Chatime memiliki pengaruh secara signifikan terhadap keputusan pembelian konsumen, variabel iklan emosional (X2) pada Chatime memiliki pengaruh secara signifikan terhadap keputusan pembelian konsumen dan variabel diskon (X3) pada Chatime memiliki pengaruh signifikan paling besar terhadap keputusan pembelian konsumen.

Dalam penelitian ini memiliki beberapa kelemahan, yaitu referensi literatur atau penelitian terdahulu mengenai label produk dan iklan emosional masih terbatas, penelitian ini tidak menggunakan variabel penghubung atau variabel mediasi, dan penyebaran angket dalam penelitian ini hanya dilakukan secara online. Untuk penelitian selanjutnya diharapkan dapat melakukan penelitian lebih lanjut mengenai label produk, iklan emosional dan diskon terhadap keputusan pembelian konsumen, sehingga dapat diketahui sejauh mana pengaruhnya. Kemudian untuk penelitian selanjutnya sebaiknya menambahkan variabelvariabel lain seperti variabel perceived social status. Penelitian selanjutnya juga dapat angket terbuka 
untuk mendapat inshight lebih mendetail dan menggunakan angket online dan offline untuk mendapatkan informasi yang luas.

\section{DAFTAR PUSTAKA}

Ahmad, Syed Ali, Mehmood, W., Ahmed, S. A., Mustafa, M., Khan, M. F. T. K., \& Yasmeen, M. (2015). Impact of Sales Promotion on consumer buying behavior in Pakistan. International Interdisciplinary Journal of Scholarly Research, 1(3), 13-22. Retrieved from https://www.srpublishers.org/uploads/4/3/6/9/43696183/_impact_of_sales_promotion_on_cons umer_buying_behavior_in_pakistan.pdf

Chatime. (2020). About - Indonesia. Retrieved July 9, 2020, from https://indonesia.chatime.com.tw/ website: https://indonesia.chatime.com.tw/about/

Fah, B. C. Y., Foon, Y. S., \& Osman, S. (2011). An Exploratory Study of the Relationships between Advertising Appeals, Spending Tendency, Perceived Social Status and Materialism on Perfume Purchasing Behavior Benjamin Chan Yin Fah Yeoh Sok Foon Centre of Excellent for Sustainable Consumption Studies. International Journal of Business and Social Science Vol., 2(10), 202209.

Fajriani, H., Suharyono, \& Bafadhal, A. S. (2018). Pengaruh Daya Tarik Iklan Rasional dan Daya Tarik Iklan Emosional Terhadap Keputusan Pembelian (Survei Online Pada Konsumen Wanita Muslim yang Membeli Produk Sunsilk Hijab di Kota Malang). Jurnal Administrasi Bisnis (JAB), 61(3), $163-171$.

Ghozali, I. (2016). Aplikasi Analisis Multivariate dengan Program IBM SPSS 23 (Edisi 8). Semarang: Badan Penerbit Universitas Diponegoro.

Ilsanti, R., Rachma, N., \& Hufron, M. (2019). No Title. Jurnal Riset Manajemen, 75-87.

K'ombwayo, C. O., \& Iravo, M. A. (2018). The Influence of Consumer Sales Promotion on Buying Behavior of Three-Wheeled Vehicles in Nairobi County. International Journal of Scientific and $\begin{array}{llll}\text { Research } & \text { Publications } & \text { (IJSRP), } & \text { 459-474), }\end{array}$ https://doi.org/https://doi.org/10.29322/ijsrp.8.11.2018.p8350

Kamran, Q., \& Siddiqui, D. A. (2019). The Impact of Iklan emosional on Consumer Buying Behavior for Home Appliance Products in Pakistan. Business and Management Horizons, 7(1), 23. https://doi.org/10.5296/bmh.v7i1.14410

Kontan. (2017). Inovasi dan promosi jadi strategi bisnis Chatime.

Kotler, P., \& Armstrong, G. (2008). Prinsip-Prinsip Pemasaran. Jakarta: Erlangga.

Kotler, P., \& Keller, K. L. (2009). Manajemen Pemasaran Jilid 1 (Edisi 13). Jakarta: Erlangga.

KumparanFOOD. (2019). Cerita Boba, Bubble Drink yang Digandrungi Anak Muda. Retrieved May 12, 2020, from kumparan.com website: https://kumparan.com/kumparanfood/cerita-bobabubble-drink-yang-digandrungi-anak-muda-1rPinRkuKoA/full

Limbong, E. G., \& Winarni, R. W. (2017). Daya Tarik Emosional dalam Iklan Coca Cola Versi "Rayakan Namamu" sebagai Kampanye Anti-Bullying. Jurnal Desain, 4(03), 163. https://doi.org/https://doi.org/10.30998/jurnaldesain.v4i03.1607

Majalah Serpong Update. (2018). Chatime Luncurkan Kartu Member Terbaru Berbentuk Daun | Serpong Update. 
Muhammad Akbar Marzuq \& Anik Lestari Andjarwati. Label Produk, Iklan Emosional, dan Diskon serta Pengaruhnya terhadap Keputusan Pembelian

Mowen, J., \& Minor, M. (2002). Perilaku Konsumen. Jakarta: Erlangga.

Muzhar, A., Santoso, B., \& Rusdan. (2018). The Effect of Halal Label on Brand Image and Its Impact on Consumers ' Purchasing Decisions. The International Journal Of Business \& Management, 6(2), 171-180.

Nasution, Muhammad Dharma Tuah Putra, \& Rossanty, Y. (2018). Country of origin as a moderator of halal label and purchase behavior. Journal of Business and Retail Management Research, 12(2), 194-201. https://doi.org/10.24052/jbrmr/v12is02/cooaamohlapb

Palupi, D. H. (2020, June 17). Chatime, Terapkan Strategi Agresif dan Inovatif | SWA.co.id. Retrieved July 9, 2020, from swa.co.id website: https://swa.co.id/kumparan/chatime-terapkan-strategiagresif-dan-inovatif

Ribeiro, A. P. L., Carneiro, J. de D. S., De Melo Ramos, T., Patterson, L., \& Pinto, S. M. (2018). Determining how packaging and labeling of Requeijão cheese affects the purchase behavior of consumers of different age groups. British Food Journal, 120(6), 1183-1194. https://doi.org/10.1108/BFJ-02-2017-0081

Shamout, Mohammed Dawood. (2016). Impossible dream or inevitable revolution? Investigating the concept of integrated marketing communications. Journal of Communication Management, 2(1), 70-81. https://doi.org/10.1108/eb023449

Simamora, H. (2000). Manajemen Pemasaran Internasional Jilid 1. Jakarta: Salemba Empat.

Sugiyono. (2017). Metode Penelitian Kuantitatif, Kualitatif, dan R\&D. Bandung: Alfabeta.

Sumarwan, U. (2015). Perilaku Konsumen (Edisi kedu). Jakarta: Ghalia Indonesia.

Tjiptono, F. (2008). Strategi Pemasaran (Edisi 3). Yogyakarta: ANDI.

Top Brand Index. (2020). Top Brand Index Beserta Kategori Lengkap | Top Brand Award. Retrieved May 12, 2020, from topbrand-award.com website: https://www.topbrand-award.com/top-brandindex/

Wijayanto. (2019, August 3). AFI: Bisnis Waralaba Masih Kalah dengan Pemain Asing. Retrieved July 9, 2020, from radarsurabaya.jawapos.com website: https://radarsurabaya.jawapos.com/read/2019/08/03/149362/afi-bisnis-waralaba-masih-kalahdengan-pemain-asing 